\title{
Arguing Away Suffering: The Neo-Cartesian Revival
}

\author{
Evelyn B. Pluhar \\ Pennsylvania State University
}

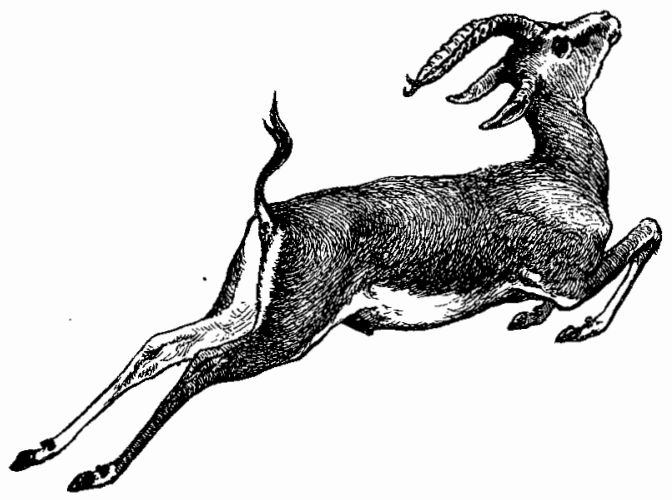

Generally, people who have had the opportunity to observe nonhuman animals, especially vertebrates, for any length of time take for granted that these beings are conscious and capable of suffering. If we are pressed to give a rational defense of this belief, we can have no better start than the inductive argument from analogy to other minds from one's own case. Beings who are neurologically highly similar to me and who respond in complex, creative ways to stimuli that also elicit my responses are probably conscious just as I am. This is an extraordinarily strong inductive argument, fulfilling all criteria for good two-case analogical reasoning, licensing one to infer that another, be the other human or nonhuman, is not merely a cleverly contrived machine. ${ }^{1}$ Those who are skeptical about induction as such are, of course, not persuaded by the argument, but they also cannot be persuaded about the existence of their own bodies, let alone anyone else's. Short of solipsism, one seems not to be irrational in putting one's confidence in the argument from analogy.

René Descartes had doubts about the extension of this argument to nonhumans: This

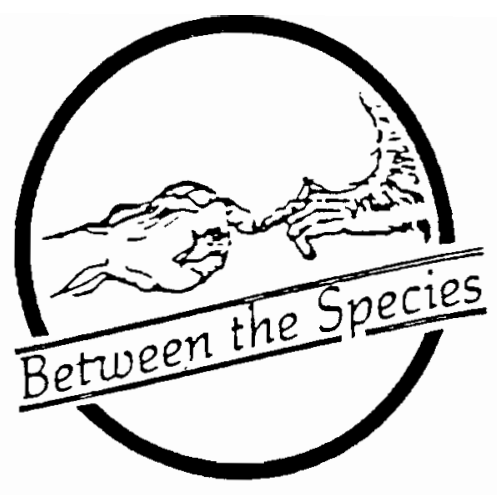

argument, which is very obvious, has taken possession of the minds of all men from their earliest age. But there are other arguments, stronger and more numerous, but not so obvious to everyone, which strongly urge the opposite. One is that it is more probable that worms and flies and caterpillars move mechanically than that they all have immortal souls. ${ }^{2}$

Philosophically, Descartes' counter to the argument from analogy is not plausible for many reasons, ${ }^{3}$ including the fact that it is wedded to a version of mindbody dualism fraught with well-known difficulties. Scientifically, the argument from analogy has grown even stronger since Descartes' time. It has been buttressed by centuries of observation, much of it done at great cost to nonhuman animals, that reveal complex, detailed similarities between human and nonhuman vertebrate nervous systems. We know that many nonhuman animals have the same pain mechanisms we do, and their behaviors are consistent with this fact. Even some invertebrates appear to have some parts of this mechanism. ${ }^{4}$ Moreover, as Bernard Rollin ${ }^{5}$ and James Rachels ${ }^{6}$ have argued, we fly in the face of the superbly confirmed theory of evolution if we assume that consciousness is a uniquely human trait. Logic, science, and common sense all point to the existence of nonhuman animal suffering.

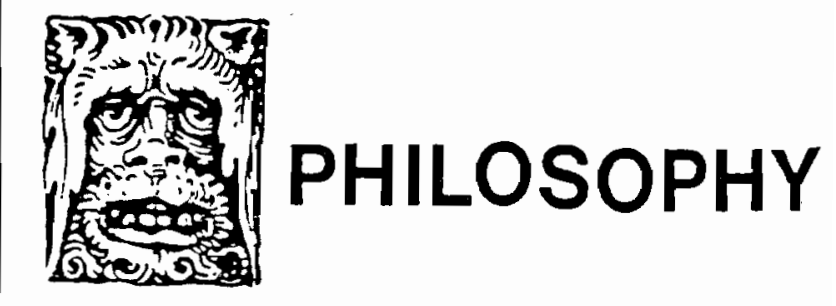


Nevertheless, as Rollin (a professor of physiology and biophysics as well as a professor of philosophy) has painstakingly documented, some scientists even to this day persist in denying that animals can experience pain, relying implicitly on the philosophically longdiscredited views of logical positivism and behaviorism. $\mathrm{He}$ is cautiously optimistic about the fact that it is becoming scientifically respectable once more to attribute conscious states to nonhumans in the social and natural sciences. ${ }^{7}$ Ironically, if two current philosophers, Peter Harrison ${ }^{8}$ and Peter Carruthers, ${ }^{9}$ writing independently, have their way, scientists might as well return to the practice of nailing research animals to boards for vivisection without benefit of anesthesia. Descartes' views are with us again, albeit in contemporary dress.

Now, quite a few of us regard it as screamingly obvious that nonhuman animals can suffer. Is it not a waste of time to critique such articles? Unfortunately, it is not. Philosophers have been enormously influential in shaping attitudes toward nonhuman animals. Descartes, a scientific experimentalist whose own interest in the issue of nonhuman animal treatment was not purely philosophical, had a profound effect on the practice of vivisection. Long before anesthesia became available, experimenters taking apart yelping animals in laboratories laughed at the sounds, comparing them to clocks striking the hour. ${ }^{10}$ (Rachels notes that some researchers must have found all the noise distracting, however, finding it prudent to sever the animals' vocal cords. Some clocks do need to be muffled. ${ }^{11}$ ) Later, two hundred years after Descartes' death, Claude Bernard, a pioneer in experimental physiology, routinely vivisected complex animals, speaking of them in these terms:

It is necessary, so to speak, to take an organism to pieces in successive stages, in the same way that one dismantles a machine, in order to recognize and to study its working parts. ${ }^{12}$

Although anesthesia was in practice then, Bernard never used it, any more than he would have tried to use it on a timepiece. (His wife and daughters found themselves unable to share his views; they originated the first European anti-vivisection society after coming home one day to discover that Bernard had vivisected the family $\operatorname{dog} .{ }^{13}$ ) Even now, as Rollin reports, the occasional veterinarian (of all people) will publicly proclaim that anesthesia in operations on animals is merely a method of "chemical restraint," having nothing whatever to do with pain relief. ${ }^{14}$

As mentioned before, the philosophical movement of logical positivism has also had its influence on science: any discussion of conscious states in nonhumans (or, for that matter, humans) was ruled out as meaningless because such claims cannot be tested by observations. All claims about values fell by the wayside as well, reducing any ethical dilemmas a researcher might have to emotional, rationally irresolvable matters of taste. This view is no longer taken seriously by philosophers-for one thing, logical positivism cannot pass its own criterion of meaningfulness-but its influence can still be seen in psychology, biology, and physics. In short, philosophical views do matter in the conduct of science, particularly when these views have implications many scientists find attractive. (Scientists are hardly unique in this regard, to be sure.)

Some will find the articles by Carruthers and Harrison, with their conclusion that animal suffering is for the most part a myth, quite attractive. ${ }^{15}$ These articles come at a time when many research scientists are mounting a counterattack on those who charge that their work with nonhumans is unethical. Both articles appeared in journals of philosophy with very high reputations (indeed, Carruthers' piece was published by the journal with the top reputation in analytic philosophy in the world), and their influence is already spreading. Harrison's article has recently been excerpted in a popular anthology on nonhuman animal research. ${ }^{16}$ Defenders of factory farming, commercial hunting and trapping, and the use of nonhuman animals in product testing will likely also see these essays as contributions to their counterattacks. Both philosophers explicitly draw the obvious ethical consequences of their conclusions, Harrison only briefly_-'Such causes as animal liberation may have to be rethought"17 _ and Carruthers at greater length. He expresses indignation at the charge that factory farming involves animal cruelty, terming this attack "morally objectionable" and going so far as to declare that we have a "moral imperative" to cease feeling sympathy for nonhuman animals. ${ }^{18}$

Thus, it is important to respond to such philosophical argumentation. It is especially important that the response be rationally defensible. Otherwise, one is apt to be dismissed as a purely emotional 
anthropomorphic fantasizer when one objects to the rubbing of noxious substances into immobilized rabbits' eyes. I will argue that reason, not just emotion, severely undermines the denial of nonhuman animal suffering. Most of my time will be spent on Harrison's piece. Carruthers' article has already been ably attacked by philosopher Edward Johnson, ${ }^{19}$ so I will confine myself to additional important problems with it. In the end, it should be clear that these defenses of the animal-as-machine model are no more successful than the one Rene Descartes proposed in the midseventeenth century.

\section{Harrison's Attack on Nonhuman Animal Suffering}

Peter Harrison tries to turn the supporting evidence for the argument from analogy on its head. He argues that evolutionary theory actually undercuts the assumption that nonhumans can experience pain. He denies the relevance of the copiously documented similarities between human and nonhuman animals. Overall, he claims to be defending Descartes' conclusion without the encumbrance of Descartes' metaphysics. His purpose is explicitly theological. He believes that the existence of human suffering can be reconciled with the existence of God because (a) suffering caused to humans by humans is the price of free will and (b) suffering due to natural causes builds human character. On the other hand, he believes that nonhuman animal suffering cannot be explained away in these terms. ${ }^{20}$ Thus, he quite literally explains it away in other terms, i.e., by denying that there is any such phenomenon. (As we shall see, he also must deny the existence of suffering in very young children-a decided theological bonus). The argument he gives to convince us is, he warns us, not a "strict" argument against the existence of nonhuman animal pain, due to the fact that pain is essentially private, ${ }^{21}$ but he does claim to make a plausible case for his contention. Let us now turn to his argument.

\section{A. Why nonhuman animal pain allegedly does not exist}

Harrison's argument can be summarized as follows:

1. Many kinds of pain could have no evolutionary value for nonhuman animals; quite the contrary. This includes frustration, anxiety, grief, and severe debilitating pain.
2. We know humans experience such pains (or that we do, at any rate!); we survive them because we are insulated by our cultures from the effects of natural selection.

3. Other, lesser pains would have no evolutionary value to nonhuman animals either, because:

a. Nonhuman animals can make no choices. Survival-enhancing behavior can be determined without the "superfluous" experience of pain, as studies of reflex actions show.

b. The argument from analogy that leads us to believe otherwise is bad because

(1) so-called "pain behavior" in nonhumans is no more than an adaptive response, as is shown by the different behaviors of, e.g, a wildebeest and a chimp in circumstances we would find painful.

(2) The very minimal difference in physiology between humans and nonhuman animals has no bearing on pain: "It has long been recognized" that pain is an overwhelmingly psychological phenomenon because:

(a) Aristotle, Spinoza, and Ryle hold that pain is not really a sensation.

(b) Psychological factors can play a major role in pain perception.

c. Nonhuman animals could "learn" from experiences we would find painful, thus enhancing their survival chances, without having any conscious experiences at all, as is shown by studies of habituation in protozoa.

4. Humans experience lesser pains, as we know, not to ensure our survival (see 2), but to "free us from instinct" when we choose to endure or not endure pain. All pain is a complex phenomenon experienceable only by highly developed "conscious egos." Nonhuman animals lack the complexity required for consciousness.

Therefore, it is highly probable that humans differ from nonhumans in having a capacity to experience pain. 
The rationales for Harrison's major contentions will be discussed, followed by responses to those rationales.

The contention that evolutionary theory rules out severe, debilitating pain and "mental" pain such as anxiety, grief, frustration, etc., in nonhumans

Harrison's first two premises rely on this contention. He makes this assertion on the simple ground that such pains have no survival value. In fact, pains of this kind often interfere with one's survival. Hence, "the canons of evolutionary dogma" do not permit the attribution of such experiences to nonhuman animals. Humans, on the other hand, do have such experiences, as one knows from one's own case. We have them despite their unhelpful consequences because we have "thwarted natural selection:" human culture in general insulates us from the ravages of nature, keeping such painful experiences from threatening human existence. ${ }^{22}$ Thus, evolutionary theory is allegedly compatible with the existence of these experiences in humans but incompatible with their existence in nonhumans.

This contention is inadequately supported for a number of reasons. First of all, Harrison simply misunderstands evolutionary theory. No evolutionary biologist would claim that every trait possessed by a typical member of a species has to have survival value. As Stephen Jay Gould puts it, "[the] imperfection of nature reveals evolution." ${ }^{23}$ Very colloquially speaking, a large part of inheritance is a crap shoot. Variation is due to mutations, which are copying errors in the genetic code, and most of these mutations are neither enormously helpful nor destructive. Individuals can survive and pass on their traits even if some of those traits are not particularly advantageous and might at times even interfere with survival. As Niles Eldridge says, "[that] some of these biological mistakes may ul timately prove to be beneficial is all evolutionists have ever claimed."24 It is individuals with their collection of more or less beneficial, neutral, and harmful traits who are subject to natural selection, not the individual traits themselves. ${ }^{25}$ Harrison also does not consider the possibility that a trait may be harmful in some circumstances and beneficial in others (intelligence is one trait that comes to mind in this connection) or that it may be harmful in the short run but useful in the long run. For example, frustration might lead one to make beneficial changes in one's circumstances; grief is the consequence of caring, a trait that strengthens bonds with one's offspring; chronic pain may be destructive, but the mechanism responsible for it could be very constructive indeed in other circumstances. ${ }^{26}$ Moreover, Harrison provides no independent grounds for thinking that nonhumans cannot experience grief, anxiety, frustration, or chronic pain. To Harrison, the behavior of a cat or dog who ceases to eat when a companion human or nonhuman dies must be inexplicable, as would be the behavior of closely confined nonhumans in zoos, on farms, and in research laboratories. Even the most unsentimental nonhuman animal scientists are beginning to speak openly about such states in their subjects. ${ }^{27}$ "Porcine Stress Syndrome" (PSS) and "mourning behavior" in tightly restrained sows are conditions identified and named by the pork industry itself. Psychologists whose research involves the induction of grief, anxiety, anguish and psychosis in nonhumans would also disagree with Harrison.

Harrison also gives us no good reason to believe that humans differ fundamentally from nonhumans in their experiences of "harmful" pains. No evidence whatever is given to support his contention that humans alone have escaped the strictures of natural selection. Did primitive humans hundreds of thousands of years ago have no such experiences? Or did they somehow "thwart" natural selection as modern humans allegedly have? Presently, one might say that in some societies medical care allows us to save those who would otherwise die before being able to reproduce, but this has only been so for a short while in human history, and not universally so even then. It is also simply false to say that debilitating pain, depression, anxiety, etc., do not threaten our survival. Stress-related severe illnesses, cancer included, not to mention suicide, indicate otherwise. Harrison even quotes, to support his own view, a researcher's claim that chronic human pain interferes with human survival. ${ }^{28}$ By his own argument above, employed against the possibility of such experiences in nonhumans, humans should also not be capable of them. If he were to reply that the human species as a whole is able to continue despite these individual deaths because most of us do not succumb to these very negative pains or are able to replace our deaths with the lives of offspring, why could this not also be true of nonhumans? Contrary to Harrison, evolutionary biologists see continuity rather than discontinuity between nonhumans and humans. Allan C. Wilson argues that "the brain of mammals and birds" can itself drive evolution by allowing members 
of a species to begin interacting with a habitat in new ways, ways that themselves expose members of the species to new selection procedures, leading to the perpetuation of individuals with different traits. ${ }^{29}$ Wilson is hardly alone in attributing ingenuity, creativity, and intelligence to nonhumans. ${ }^{30}$ Why shouldn't "negative" traits also be shared by humans and nonhumans?

In short, Harrison has not shown that evolutionary theory supports his view that only humans could experience seriously harmful pains (premises 1 and 2). Instead, there is good reason to believe otherwise.

\section{The contention that "lesser" pains would also have no evolutionary value for nonhumans}

Having rejected the view that nonhumans are capable of complex, counter-productive sorts of pain experiences, Harrison goes on to consider the claim that the ability to experience simple, useful pains would confer an adaptive advantage on nonhuman animals. He rejects this claim as well (premise 3 above), primarily on the grounds that the point of such a mechanism would be to allow the animal to make survival-enhancing choices. Since, in Harrison's view, no nonhuman is capable of making a choice, such a mechanism would be gratuitous at best:

If no 'choice' is involved in animal behavior, why should they suffer pain-to compel them to behave in certain ways? No, for surely their behavior is determined in a way that does not require the superfluous promptings of pain. ${ }^{31}$

This stage of Harrison's argument (premise 3a) is faulty for at least two reasons. First, he relies on the undefended assumption that the capacity to choose is incompatible with the deterministic thesis that all behavior is caused by events which are in turn caused, etc. The classic problem faced by such a view is how to construe an uncaused choice in a meaningful way, not merely as an inexplicable, random event. If we reject the view that choice and causation are incompatible (i.e., the view that all causation must be compulsion), it makes perfectly good sense to interpret pain as part of the causal sequence leading to a wolf cub's refusal to play with the next porcupine in her path. Why should the experience of pain be "superfluous" in this series of events? I can fathom but one reason for such a claim:
Harrison seems to be assuming that conscious experiences can have no role in nonhuman animal behavior. Pain would be unnecessary because, allegedly, the nonhuman animal simply responds, puppet-like, to the external forces acting upon her. ${ }^{32}$ Pain in these circumstances would not be survival-enhancing. Yet, this is the very thesis that Harrison is trying to persuade us to accept: the thesis that animals are machines. He can hardly convince us of this thesis by appealing to it in his premises! This leads to the second and related major problem with Harrison's line of argumentation here. He simply assumes without argument that only humans can make choices. Since considerable, respectable evidence to the contrary has been amassed by ethologists, ${ }^{33}$ Harrison should at least address that body of information. He makes no such attempt.

Instead, Harrison now turns to the argument from analogy, rightly recognizing that it seems to provide powerful support for the contention that animals can experience at least simple pains. He rejects it for two reasons. First of all (premise $3 b-1$ ), he judges it to be scientifically unsupported, fanciful thinking:

we tend to presume that certain animal behaviors are expressions of pain-an internal state-whereas they should properly be construed as adaptive behaviors which probably have some social significance. ${ }^{34}$

Harrison asks us to consider a wildebeest being killed by wild dogs and a chimpanzee with a thom in his foot. The chimpanzee screams pitiously, "as if in pain," but the wildebeest makes no outcry. ${ }^{35}$ The chimpanzee behaves as we expect, the wildebeest does not, but each is responding in a generally "adaptive" way: it is to chimpanzees' advantage in thomy situations to get aid; it is not to wildebeests' advantage to expose the rest of the herd to predators. Neither, Harrison assumes, is really experiencing pain; they are simply doing evolution's bidding.

This is not a convincing attack on the argument from analogy. Harrison's claim that nonhuman animal behaviors are adaptive rather than expressions of pain is a clear instance of the fallacy of false dilemma. Behaviors can be expressions of pain and have adaptive significance as well. Harrison thinks not, presumably because he believes that his wildebeest-chimpanzee example shows (a) the wildebeest experiences no pain and (b) there is no reason to think that chimpanzees 
differ from wildebeests in this regard. He considers the possibility that both might be experiencing pain, but turns it into a "straw possibility" by caricaturing that position. He describes the belief that the chimpanzee is being an oversensitive coward whereas the wildebeest is stoically enduring agony as "crudely anthropomorphic." ${ }^{36}$ This may be so, but it does not show the belief that the two are expressing their pain differently to be anthropomorphic. We must indeed guard against using the argument from analogy in a simplistic way, but it is Harrison who is guilty of doing this here, not those who believe that nonhumans can experience pain. In fact, Rollin has argued that those who deny that nonhumans could be experiencing pain if they do not behave exactly as we do are the ones guilty of anthropomorphism. ${ }^{37}$

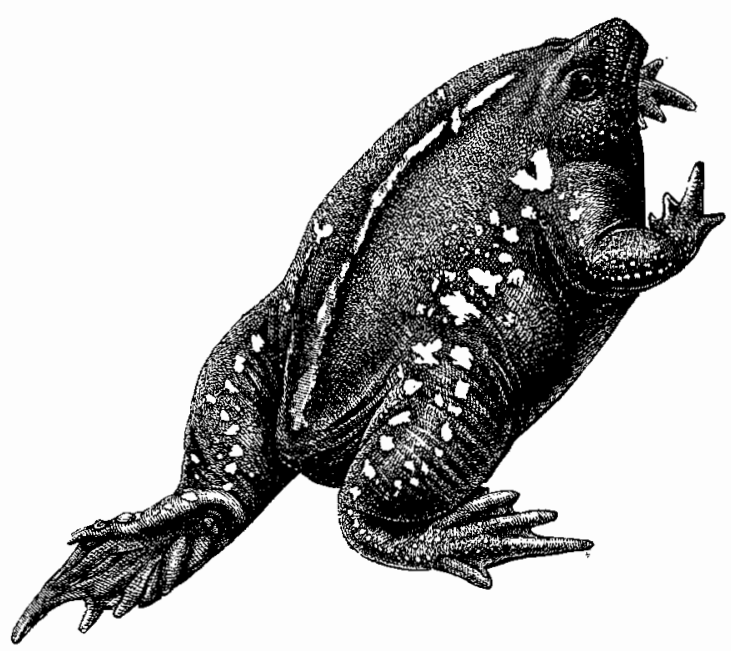

The view that vertebrate nonhuman animals can experience pain is consonant with the neurophysiological similarity of human and nonhuman species--a similarity Harrison fully concedes ${ }^{38}$-and evolutionary theory. Humans generally yell, just as our $98.4 \%$ genetically similar chimpanzee cousins do, when we get large thorns in our appendages. We also happen to be experiencing pain when we do this; is it anthropomorphic to believe that chimpanzees do too? As for the wildebeest, who possesses the same nervous system that is linked to pain perception in our case, behavior that does not endanger the rest of the herd obviously does have an adaptive advantage; this is compatible with the suffering of the animal. There is yet another alternative. Humans have reported that sometimes, at times of great physical trauma, physical damage that one would expect to cause excruciating pain is somehow suspended. Later, if one survives the trauma, the pain comes roaring in. This phenomenon is known as "stressinduced analgesia." 39 A response of this kind would be advantageous, not only to the individual who is momentarily spared agony, who may then be able to concentrate on fighting for life or at least not die instantly of shock, but to the species as a whole. Perhaps the wildebeest, and others in similar circumstances, is being naturally anesthetized. While we can hope that this is so, such a possibility must remain speculative at this point.$^{40}$ Note, however, that this interpretation of the wildebeest's behavior is fully compatible with the argument from analogy: it grows out of human reports, is in line with our similar physiologies, and actually contradicts Harrison's claim that only humans are capable of pain perception (and hence of being anesthetized). Harrison has not shown his machine model of nonhuman animal behavior to be more plausible than either the suffering or the stress-induced analgesia hypotheses.

At this point, Harrison launches his second attack on the argument from analogy (premise 3b-2). Since he cannot and does not deny that there is between humans and many nonhumans an overwhelming physiological similarity in respects relevant to pain perception, he chooses to dismiss the importance of this similarity instead. He cites Aristotle, Spinoza, Ryle, and some twentieth-century psychological research to buttress his view that "pain is associated with 'higher' faculties, the study of which is more properly psychological than physiological." ${ }^{41}$ He then leaps to the conclusion that pain is primarily a psychological phenomenon, joins it to the conclusion that psychological factors do not operate in nonhumans, and asserts that "[a]11 human experiences of pain, I have argued, are functions of our distinctive consciousness, and thus cannot be shared by our furry friends." 42 Harrison claims to be eschewing Cartesian dualism in drawing this overall conclusion: he holds that we, unlike him, commonly assume that nonhumans experience pain because we associate pain with the body and more complex pains such as frustration, anxiety, etc., with the mind: thus the common view is (supposedly) that nonhumans are capable of the former but not the latter. 
This won't do. Despite his disclaimer, Harrison is the one who appears to cling to Cartesian dualism, construing all pain as part of the mind rather than the body. He provides no evidence sufficient to establish this sweeping conclusion (eminent as Aristotle, Spinoza, and Ryle were, they have been known to be wrong, and the psychological studies he cites from the 1950 s are either thoroughly outdated by current research ${ }^{43}$ or irrelevant to the dismissal of physiology in favor of psychology). No one these days denies that beliefs and emotions can affect pain perception: it does not follow from this that pain is a psychological rather than a physiological phenomenon. Moreover, Harrison does not address the evidence that nonhumans apparently can also be affected by psychological factors when they are in situations we would regard as painful in our own cases (e.g., as is the case for humans, companion nonhuman animals show less "distress" when ill if they are treated kindly rather than coldly and clinically). ${ }^{44} \mathrm{His}$ argumentation on this head is quite simply question-begging: pain is primarily psychological (an unsupported contention); nonhuman animals have no psyches to speak of (also unsupported); thus nonhuman animals experience no pain. They are machines because they are machines.

Finally, in his attempt to show that a pain mechanism would provide no evolutionary advantage to nonhumans, Harrison tries to show that they could "learn" from experiences that would cause pain to us without being conscious at all (premise 3c). When we touch a very hot surface, we instantly, reflexively, withdraw; the experience of pain comes after the withdrawal, so the experience has not caused us to act. Harrison believes this shows conscious awareness of pain to be unnecessary for the production of survival-enhancing behavior. ${ }^{45}$ Thus, he holds, evolutionary processes would not favor the emergence of a capacity for pain in nonhumans. (He recognizes that this poses a puzzle for the existence of human pain. His way of trying to resolve that puzzle will be discussed below.)

Once again, this line of argument fails to support Harrison's conclusion. Withdrawing from a flame is indeed a reflex action rather than a consciously motivated response to pain, but avoiding the flame the next time is another matter. Nonhumans are at least as likely as humans to avoid situations of this kind after their initial occurrence. This can hardly be construed as reflex action, and it is difficult to see how it would occur if a painful experience had no part in the prior incident. In our own case, pain seems to be highly instructive, as humans who lack the pain mechanism discover (provided they live long enough to arrive at that realization). Nonhumans do not behave as if they could never experience pain; they behave as if they learn from it. As Harrison himself admits, nonhumans are used in pain research and can be, as he puts it, "conditioned by "pain." "46

The best that Harrison can do in trying to make sense of the fact that nonhumans can learn from nonexistent pain is to cite the example of protozoan "learning." He cites a study in which these one-celled beings exhibited habituation to a repeated stimulus ${ }^{47}$ Clearly, he thinks, this shows that learning ("learning"?) does not require consciousness. Although he denies that he is claiming that all learning in nonhumans is of this sort, this must be what he believes, given his machine model. Yet this sort of response by a one-celled organism bears no relation to a wolf's refusal to tangle with her second porcupine, a dog's cowering away from a human who has beaten him but once before, or a goat's avoidance of an electrified fence that once gave her a shock. These are not acts of blind habituation. Harrison gives us no way to fathom these behaviors.

Harrison, therefore, has not shown that the capacity to experience pain would have no evolutionary advantage for nonhumans. What of the fact that humans, who have also evolved, do experience pain? Harrison turns to this question in his premise 4 .

\section{The explanation of human pain}

"Why do we feel pain if animals do not?," asks Harrison. ${ }^{48}$ He makes no attempt to relate the capacity for pain to an evolutionary advantage for humans, despite his admission that humans who lack the capacity are not long for this world. ${ }^{49}$ Of course, it would be difficult for him to argue that the experience gives humans an adaptive advantage when he believes he has shown that it provides no such advantage to nonhumans. Moreover, his contention that humans are not subject to natural selection pressures (premise 2) would be in direct contradiction to such an attempted explanation. The explanation he does provide is rather curious. He holds that humans, unlike nonhumans, are capable of freedom of choice, and pain allegedly enables us to act deliberately rather than instinctively. Harrison believes that the capacity for pain is a necessary condition for freedom of the will: 
What is distinctive about the human race is our ability to choose... We are free, in painful situations, to damage our bodies if we believe that there is a higher priority...Pain frees us from the compulsion of acting instinctively; it issues harsh warnings, but they are warnings which may be ignored. It is our capacity for pain which has given rise to those uniquely human attributes of courage, resignation, self-control, perseverance, endurance, and their opposites, and it is significant that we reserve these terms for ourselves...Free will is at the high cost of suffering, but it is a suffering which is rightly restricted to the human realm. ${ }^{50}$

This is a very puzzling argument. First of all, pain seems to be more a hindrance than a help to choicemaking as Harrison conceives it. Wouldn't it be a great deal easier to defy "instinct" if we were not subject to pain? We normally act to avoid being burned, stabbed, kicked, etc., just as many nonhumans do. (In the world as it has developed this helps us one and all to survive, but this line of argument is not open to Harrison, as we saw above.) Now, I do not claim that such avoidance behavior is unfree (unlike Harrison, I do not think that freedom and causation are incompatible), but Harrison is reaching for a concept of freedom that is unique to human behavior. He has not shown us how pain "frees us [in his sense] from the compulsion of instinct."

Harrison might reply that only humans can act despite pain; i.e., we are uniquely capable of courage, endurance, perseverance, etc. This is freedom in the highest sense, one might hold, the putting of other considerations over our own well-being. Without pain, Harrison could say, we have no barometer of well-being, and terms like"courageous" become empty (as do terms like "cowardly"). Nonhumans, however, sometimes behave as if they, too, defy pain. When we behave in these ways, we garner moral credit for ourselves; when they do, Harrison regards them as machines. He is not the only one to engage in double-standard thinking here: a human mother who attacks an armed criminal threatening her children, risking injury and death, is "heroic" and "courageous;" a harp seal mother who charges a seal hunter, finally throwing herself across her pup, taking the skull-shattering bashing intended for her offspring, is "just acting instinctively!" Harrison may take it for granted that we reserve praiseworthy terminology for ourselves, but it is far from clear that this is justified. ${ }^{51}$

Why, indeed, should humans be able deliberately to flout their own well-being and nonhumans be incapable of doing such a thing? What naturalistic explanation could account for such an alleged difference? Certainly, deliberate action requires some intelligence, but as Harrison concedes in a footnote, ${ }^{52}$ nonhumans can display high degrees of intelligence, too. Human children and some brain-damaged humans can also act in self-sacrificial ways, and their intellectual development may not differ significantly from the corresponding capacities of some nonhumans. I strongly suspect that Harrison has no naturalistic explanation of the difference he (and many others) believes to obtain between human and nonhuman behaviors. The language in his remark that "[f]ree will is at the high cost of suffering, but it is a suffering which is rightly restricted to the human realm" is redolent of a theological explanation. Harrison, remember, is grappling with and trying to defeat the argument from evil against the existence of God. As he sees it, human suffering must be good for us, make us better persons; since he seems to take for granted that nonhumans are not capable of such betterment, he finds it necessary to deny that they suffer at all. Those without Harrison's theological presuppositions will be left unconvinced by such argumentation. ${ }^{53}$

Finally, it is not difficult to conceive of a being who could make choices-including morally praiseworthy choices-without ever experiencing pain; God would be an outstanding case in point. Nor need we reach so high or so controversially for an example: surely Harrison would not claim that humans who lack the capacity for pain are unable to make choices.

Thus Harrison has failed on all counts in his attempt to show that the experience of pain is a necessary condition for an allegedly unique human ability to make choices. Premise 4 has failed just as resoundingly as premises 1-3. Harrison's overall argument consists of a series of inadequately supported statements, hasty generalizations, and question-begging assumptions. The assumptions that nonhumans cannot make choices, consciously learn, or have even undeveloped psyches, already portray them as machines. Humans, by contrast, are portrayed as free, uniquely insulated from natural selection, potentially magnificently brave, virtuous 
beings. Seldom since the days of Descartes has the deck been stacked so high against nonhumans.

Harrison seems to realize that his argument is unconvincing. The last part of his article now takes a stunning turn: he appears to concede that nonhumans can experience pain, but denies that this pain could be significant.

\section{B. Why nonhuman pain is allegedly insignificant}

Harrison begins by providing us with a series of thought experiments to help us imagine what it would be like to act as if one is in pain in response to stimuli that we find painful and "yet not feel pain." ${ }^{.}$. However, the examples he goes on to sketch are really meant to support the conclusion that any pain felt by a nonhuman is experientially and morally insignificant. Long before Harrison's day, Descartes also appeared to be running both these lines simultaneously. Although he assured us that nonhumans could only be automata, he also claimed that they were capable of sensation. 55 Occasionally, an ambiguity hides the contradiction (e.g., Harrison's assertion that "animals do not experience pain as we do," 56 ) but a contradiction it nevertheless is.

Harrison asks us to imagine three cases: a man who has violent nightmares that he never remembers, a drug that immobilizes one without anesthetic and makes one forget any pain that occurred under its influence, and our inability to remember any pain suffered as infants. The common thread in these cases is the inability to recall pain. Surely, Harrison presses, such experiences must be insignificant. Only experiences that we can sort in with our other experiences can be "owned" by us. ${ }^{57}$ Nonhumans, Harrison assumes without argument as he has throughout his discussion, are like infants: they "have no self," are mere bundles of discrete sensations, are incapable of doing any such sorting, of remembering that they have been in pain. ${ }^{58} \mathrm{He}$ no longer claims that pain has not occurred: "I am not implying here that painful experiences which are forgotten were never painful to start with." 59 However, significant pain requires "a continuity of consciousness" open only to older humans (unless, of course, one is greatly mentally impaired - a possibility conspicuously absent from his entire discussion, although it poses well-known problems for theodicy.)

Harrison is no better off going with this half of the contradiction than he was in denying pain altogether to nonhumans. First, Harrison does not begin to show that nonhumans have insufficient continuity of consciousness to remember pain. Once again, the double standard clicks into place: when I avoid the bully who beat me senseless yesterday, I am remembering my painful experience and acting appropriately; when Beauregard Beagle cowers away from the human who kicked him repeatedly yesterday, he is gripped by unconscious instinct ${ }^{60}$ Second, even if he were correct in claiming that nonhumans and some humans cannot remember pain, this could hardly render insignificant the pain that he admits takes place. I could beat you mercilessly, then give you a drug that would remove all your memories of the beating. Plainly, your suffering would still be immense, and I would be wronging you by inflicting it. As Rollin points out in discussing a similar view, if it were really true that nonhumans could remember no past pain, during a time of suffering they would be incapable of remembering pain's absence; thus they would be trapped in an agonizing, unending present. ${ }^{61}$ How could one be justified in focusing on the beings they will become in the future, when as Harrison has it they will have forgotten, rather than on the beings who are suffering right now? Surely, one owes more to someone who is suffering than to someone who is oblivious to suffering, especially if we are ourselves inflicting the pain!

It is now necessary to speak for human infants, who have been tarred with the same brush applied to nonhumans. The degree to which infants have continuity of consciousness is debatable: their nervous systems are less well developed than the nervous systems of adult mammals. Still, the parts of the nervous system linked to pain perception are all functional. All the neurophysiological equipment necessary for pain perception in humans (and for vertebrates in general) is present in those humans well before birth, at 25 to 26 weeks after conception. (This also holds for many nonhumans during the last (rimester.) ${ }^{62}$ Although Harrison asserts that "we regard neonatal pain as less significant than pain which is experienced later in life," ${ }^{63}$ we have excellent reason to believe that this pain can be very significant indeed. For many years, in fact, doctors assumed that infants felt little or no pain, or at least no serious pain, even during major surgery, which was routinely performed without anesthesia or (more recently) with only light anesthesia. ${ }^{64}$ Neurologists no longer believe this to be the case. Carefully controlled studies have shown that 
human neonates who are deeply anesthetized during surgery have greatly reduced levels of hormones associated with stress in their blood afterwards, cry less in the days after the operation, and, most importantly, have a much better chance of surviving than traditionally treated infants. Even infants undergoing a relatively minor operation like circumcision show benefits from local anesthesia: they cry much less during and after the procedure and have lower levels of stress hormones than their unanesthetized counterparts. ${ }^{65}$ In fact, it is now thought by pain researchers that babies and very young children may experience more pain than adults, because a "damping" mechanism which helps to cut down on the severity of pain experiences does not develop until later. ${ }^{66}$ Only those who believe that mind and body are hermetically sealed compartments could think that physiology and appropriate behavior (e.g., crying) need have nothing to do with suffering. Being unable to verbalize one's pain makes it more likely that one's pain will be ignored or disavowed; this has been just as true for humans as it has been for nonhumans. Luckily, it does seem to be true that we are less able to remember pain occurring early in life than pain occurring later; that does not make the initial experience any less agonizing, or make the infliction of such pain any more permissible.

Thus, Harrison has failed to show that nonhuman (and human neonate) pain is insignificant, just as he earlier failed to show that no such pain exists. Whichever half of the contradiction one seizes, one is not rationally persuaded. Harrison provides no support whatever for his key claims about the distinction between humans (only some of them!) and nonhumans, viz., that only humans are not subject to the strictures of natural selection, are free, and possess continuity of consciousness. (How it is possible for nonhumans to be intelligent, creative, and even learn American Sign Language, as we have seen him admit in a footnote but not in his text, without a highly complex integrated consciousness is an impenetrable mystery.) Harrison is also utterly unable to show that this concatenation of allegedly unique qualities restricts suffering to normal adult humans. Opponents of the argument from evil will have to look elsewhere for a dissolution of nonhuman suffering; so will opponents of the ascription of moral status to nonhumans. Let us now turn to another participant in the Neo-Cartesian revival.

\section{Carruthers' Attack on Nonhuman Suffering}

Peter Carruthers never mentions the name of René Descartes, or refers to mind body dualism, but he clearly subscribes to Descartes' machine model of nonhumans. ${ }^{67}$ Like Descartes, he claims to show that nonhumans or "brutes," as he prefers to call themcannot suffer. Unlike Harrison, he never wavers from this contention. Note, however, some potentially confusing terminology. He does ascribe "pain experiences" to nonhumans, but he denies that a "feeling" component is logically linked to the concept of experience ${ }^{68}$ For those of us who find the concept of an experience without a feeling component to be selfcontradictory, Carruthers suggests we recast his conclusion in our own language: he is arguing for the nonexistence of pain experiences (feelings of pain)or, in fact, any experiences - in nonhumans. First, I will summarize his argument, then I will turn to a brief evaluation of it, mainly covering ground unplowed by Johnson's recent fine critique of the same article. ${ }^{69}$

\section{Why nonhumans allegedly cannot suffer}

1. Humans have two types of "experiences." conscious and unconscious (e.g., thinking about dinner while driving home and being unable to recall driving when one arrives; daydreaming about the article you are working on while, all unawares, washing and stacking dishes as usual; as a "blindsighted" person, being able to catch a ball while denying that one sees anything); unconscious experiences "do not feel like anything."70

2. The best analysis of the difference between our conscious and unconscious experiences is based on suggestions by Daniel Dennett: the former and not the latter are "available to conscious thought, " where conscious thought is itself "available to be thought about in turn."

3. It is obvious that "brutes" cannot think about their experiences in acts of thinking that can themselves be scrutinized. ${ }^{72}$

4. Although one might think that the very nature of pain is to demand our conscious awareness (in normal circumstances), to stimulate our withdrawal, this cannot be true of nonhumans, as 
argued above; the mechanism of avoidance could be in place unaccompanied by any feeling of pain. $^{73}$

5. If nonhumans, as has been argued, cannot suffer, even though they act as if they do, they are due no moral concern on our part (e.g., it is "morally objectionable" to criticize factory farming, or indeed to feel any sympathy for nonhumans). ${ }^{74}$

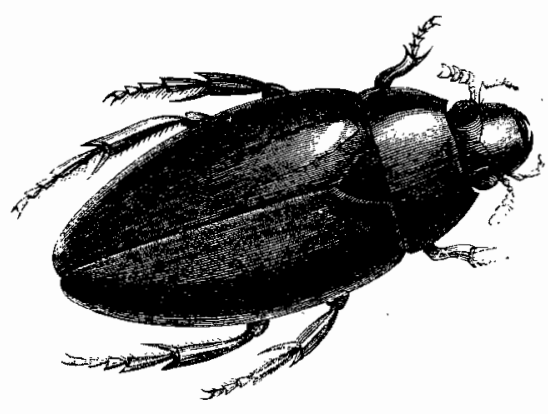

Carruthers and Harrison wrote their articles independently and had them published in the same year, preventing one from responding to the other. They have much in common, despite their very different approaches. Clearly, both Carruthers and Harrison think that nonhumans' allegedly impoverished mentalities block awareness of pain: they follow Descartes by intellectualizing suffering. It is possible, though, that Carruthers would attack the last part of Harrison's article- the argument that nonhuman pain is insignificant - as being based on the confusion of conscious with unconscious states. Carruthers might say that if (to put it in Harrison's language) there is no continuity of identity, no self, no "owning of the pain," then the nonhuman is not aware of being in pain. Now, putting it in Carruthers' terms. this would mean that the nonhuman has no conscious experience of pain: on his view, nothing hurts, even though the nonhuman behaves as if something hurts. We persist in thinking that suffering is taking place, he could say, because the argument from analogy distracts us from the vital distinction between conscious experience and machinelike behavior. This way of recasting the last part of Harrison's attack on nonhuman suffering would at least dispel the contradiction between that part and his case for the nonexistence of nonhuman pain. The initial case made by Harrison would remain as unconvincing as ever, however. Is Carruthers any more successful in making his own case for the nonexistence of nonhuman suffering? No, as I shall argue below.

\section{Carruthers' inability to account for nonhuman animal behavior}

Carruthers gives us no account of how nonhuman animals can behave as they do if all of their "experiences" are unconscious (or, to put it in the more natural way, if they have no experiences at all). Indeed, the very examples he uses to illustrate the conscious/ unconscious distinction, drawn of necessity from human experience, make no sense whatever in a context where no conscious experience has ever occurred. His dramatic example of "blindsightedness" (having no conscious experience of seeing because of lesions in the visual cortex, but being able to catch balls, identify objects, etc.) involves people who once did have conscious experiences of seeing. The same holds for the far more common examples of driving without being aware that you are, etc. Complex habitual actions can certainly occur without our being aware of them, but we had to be consciously aware of performing such actions in the first place in order to learn to do them. You cannot be a driver or a dishwasher without this initial attention. Moreover, if we sometimes do not pay attention to these actions any more, it is because we are aware of something else that distracts us from the task at hand. What would it be like to perform complex tasks, behave appropriately in changing circumstances, etc., without ever having any conscious experiences at all? Without ever feeling anything?

Carruthers does not say so, but perhaps he would respond as Harrison has in a different context, representing nonhuman behavior as largely a matter of reflex and instinct. One need not be conscious to respond if one is "programmed." However, as ethologists have shown, much nonhuman behavior is far too complex, varied, and apparently creative to represent as mere instinctual or reflex activity. I cannot resist giving a personal example here. My husband and $I$ have two feline companions, Callisto and Ganymede. Since kittenhood, the two have found the nearest bed and crawled under the blanket when loud thunder, firecrackers, or frightening strangers have made themselves apparent. It is hard enough to 
imagine them doing this while feeling nothing, but consider the next development. Just recently, in these same frightening circumstances, Ganymede began spontaneously to run to the sliding hall closet door, work it ajar with his paw, and climb into its dark recesses. Neither cat had ever done this before, and we certainly didn't encourage them to do so (our shoes are always so hairy afterwards). At first, Callisto would follow him in at those times. Now she opens the door herself, using a different maneuver: at half her brother's size, she cannot manage the task with one paw, so she flings herself to the floor, lies on her side, and uses both paws. Sometimes Ganymede runs up in the midst of this project and shoves the door ajar before she can finish; then they both scramble in. Neither of them tries to open the closet under nonfrightening circumstances. Callisto, at first a follower, soon began to go in even more often than her brother: she, always the more fearful (how else can one describe it?) of the two, breaks into the closet whenever someone rings the doorbell; he curiously (so it seems!) waits to greet the visitor at the top of the stairs. All of this behavior is explicable if one assumes that the cats are afraid, are consciously trying to gain reassurance, believe that the closet is a safe place, and are bright enough to learn how to force the closet door ajar. Moreover, neither carbon-copies the behavior of the other. How can we begin to understand what is going on if we assume that they feel nothing at all?

The background assumption of nonhuman animal consciousness fits plausibly with the hypothesis that they have unconscious experiences as well. As I write this paper, I am seldom aware of the placement of my feet (except for now!); there seems to be too much to be concerned about at any given time to open one's awareness to everything one is sensing. Nonhuman animal behavior is consistent with the same phenomenon. A cat watching a bird perched just out of reach will focus hard on the delectable item; she chatters and swishes her tail back and forth rapidly. Is she consciously aware of all this activity in her nether region? We do not know, but she seems to have eyes only for the "meal on wings." Now, gently putting your unshod foot on the cat's tail results in behavior we would call "confused" if it occurred in a human. She stops chattering at the bird, looks around at you, tries to pull away her tail, and may meow sharply at you. The intent, wide-eyed look is gone. Carruthers' description of the writer planning his paper while mechanically washing the dishes comes to mind. If a dish breaks, the content of one's awareness shifts; if someone immobilizes your tail while you are lusting after the unobtainable, you try to yank it loose. All of this human and nonhuman behavior makes excellent sense when we assume that consciousness is not an item inexplicably reserved for bipedal, peltless primates.

Carruthers has an especially difficult time explaining how "pain-like" behavior in nonhumans is to be understood. It is hard to fathom how a nonhuman whose paw is stepped on can scream, race away, and hide while feeling absolutely nothing. The only explanation Carruthers gives of such behavior is an attempted extension of the blindsightedness phenomenon. He argues that it is in principle possible for a being to act conscious when he or she is not. However, with regard to pain, he admits that there are no known human cases of having pain without feeling it, and he himself points out that the pain mechanism-a mechanism shared by nonhumans-cannot be truncated in the way the visual cortex can in blindsightedness. He even states that:

There is an obvious reason for [the lack of evidence that humans can have pain without feeling it], since part of the function of pain is to intrude upon consciousness, in order that one may give one's full attention to taking evasive action. ${ }^{75}$

This excellent logic leads one to think that nonhumans too must feel pain, but Carruthers resists the implication. He is plainly convinced that his analysis of the difference between conscious and nonconscious states has already shown that nonhumans can feel nothing. Let us turn, finally, to that analysis itself.

\section{A problem with Carruthers' analysis of the conscious/unconscious distinction}

The problem can be stated very briefly. Carruthers gives no convincing defense of his analysis of the distinction between conscious and unconscious "experiences." He defends his Dennett-based view that any conscious experience can be consciously thought about, but he does not defend his additional claim that one must be able to think about that thought in turn in order to have a conscious experience. Why should one 
have to be able to mull over one's thoughts about one's experiences in order to have the experience-to feel something - in the first place? Quite a few humans would be automata on this view! ${ }^{76}$ If one employs Occam's razor to lop off the extra layer on Carruthers' analysis, dropping the requirement that one be able to think about one's thought about one's experience, it is no longer implausible to imagine that nonhumans. (and many humans) can "think things consciously to themselves." As Johnson very rightly points out, one would think this implausible only if one requires thoughts to be expressible in a language, and Carruthers himself denies that such a requirement is necessary. ${ }^{77}$ Why shouldn't the cat be aware that she is afraid during a thunderstorm and take deliberate steps to feel safer? Carruthers' account is far less plausible than the hypothesis that this is exactly what is happening.

Thus, neither Harrison nor Carruthers has succeeded in resurrecting the Cartesian machine-model of nonhuman animals. On their views, actual nonhuman animal behavior requires a cosmic puppeteer; otherwise, it is a bottomless mystery. The real mystery here is how clever, sophisticated philosophers can lead themselves so thoroughly astray. The ad hominem fallacy is indeed to be avoided, but one cannot help wondering if Descartes and his modern counterparts would have argued as they did, had they not had such powerful incentives to deny nonhuman suffering as a devotion to vivisection, factory farming, or theodicy, and a common vision of human superiority.

\section{Notes}

\footnotetext{
${ }^{1}$ The objection that the argument is weak because one is reasoning from only one case-one's own-confuses analogical with enumerative inductive reasoning. Since one type of analogical reasoning does indeed call for enumeration of several cases in its premises, it is easy to see how the confusion arises. (For the two types of analogical inference, see, e.g., Howard Kahane, Logic and Contemporary Rhetoric, Fifth Edition, (Belmont, Ca.: Wadsworth Publishing Co., 1988), p. 304.

${ }^{2}$ Letter by Descartes to Henry Moore, reprinted in Animal Rights and Human Obligations, Second Edition, Tom Regan and Peter Singer, eds. (Englewood Cliffs, N.J.: Prentice-Hall, 1989), p. 18. The belief that other human minds exist, by contrast, is apparently "clear and distinct" enough to be warranted in Descartes' terms.

${ }^{3}$ For a detailed critique of Descartes' claims about nonhuman animals, see Tom Regan, The Case for Animal Rights (Berkeley, Cal.: U. of California Press, 1983), Chapter One.
}

${ }^{4}$ Bernard Rollin, The Unheeded Cry: Animal Consciousness, Animal Pain and Science (Oxford: Oxford U. Press, 1989), p. 154.

${ }^{5}$ Ibid., p. 154.

${ }^{6}$ James Rachels, Created from Animals (Oxford: Oxford U. Press, 1990).

${ }^{7}$ Rollin, op. cit., Chapters Nine and Ten.

${ }^{8}$ Peter Harrison, "Theodicy and Animal Pain," Philosophy 64 (247), January 1989, pp. 79-92.

${ }^{9}$ Peter Carruthers, "Brute Experience," The Joumal of Philosophy 86, 1989, pp. 258-269.

${ }^{10}$ Peter Singer, Animal Liberation, Second Edition (New York: Random House 1990), pp.201-2.

11 James Rachels, op. cit., p. 129. Animals subjected to procedures without anesthesia or analgesia still sometimes have their vocal cords tied. See Singer, op. cit., p. 29.

12 "The Growth of Anti-Vivisection," The Animals' Agenda, September/October 1988, p. 50.

${ }^{13}$ Mary Midgley, Animals and Why They Matter (Athens, Ga.: The U. of Georgia Press, 1983), p. 28.

${ }^{14}$ Bernard Rollin, "The Moral Status of Research Animals in Psychology," The American Psychologist, August 1985, 920-926, p. 924.

${ }^{15}$ The implications both men's views have for very young and very mentally handicapped humans are perhaps less attractive, as we shall see.

${ }^{16}$ It is retitled "Animal Pain" in Robert Baird and Stuart Rosenbaum, eds., Animal Experimentation: The Moral Issues (Buffalo, N.Y.: Prometheus Press, 1991), pp. 128-139.

${ }^{17}$ Harrison, "Theodicy and Animal Pain," p. 92.

${ }^{18}$ Carruthers, op. cit., p. 268 . He allows us to indulge in the belief that animals are conscious only when this belief has no "morally significant" effect on other humans (269). Depriving someone of a factory-farmed Chicken McNugget appears to count as morally significant.

${ }^{19}$ Edward Johnson, "Carruthers on Consciousness and Moral Status," Between the Species 7 (4), Fall 1991, pp. 190-92.

${ }^{20}$ Harrison, op. cit., p. 79. Human suffering is not explained away in these terms either, in my view, but that is a topic for another paper.

${ }^{21} \mathrm{Ibid}$. p. 81. He does not take note of the fact that the same problem arises, notoriously, for the assumption that other 
humans can have pain experiences. If he were asked about this, he might follow Descartes in adopting a language criterion of consciousness. Although we are not the only animals who scream, he might say, we are the only ones who scream "God, that hurts!" There are many well-known difficulties with the language criterion (see Rollin, The Unheeded Cry, Chapter Six), but there is an extra difficulty for Harrison, should he try to use it: he concedes that some nonhumans are capable of learning a language (footnote 8, p. 82).

${ }^{22} \mathrm{lbid}$, p. 82.

${ }^{23}$ Stephen Jay Gould, "Evolution as Fact and Theory," Discover, May 1981, 34-37: 36. For more discussion, see his "Darwinism Defined" in the same science magazine (January 1987, pp. 64-70), and his book Ever Since Darwin: Reflections in Natural History (New York: W. W. Norton, 1977).

${ }^{24}$ Niles Eldridge, The Monkey Business: A Scientist Looks at Creationism (New York: Pocket Books, 1982), p. 115.

${ }^{25}$ Stephen Jay Gould, Ever Since Darwin, op. cit., p. 11.

${ }^{26}$ Harrison does at least consider (then dismiss) the view that a pain mechanism would have survival value for nonhumans, as discussion of his premise 3 will indicate.

${ }^{27}$ Peter Singer, op. cit., p. 122. I observed this first-hand as an ethics discussant at the First International Conference on Farm Animal Welfare, sponsored by the University of Maryland's Departments of Animal and Poultry Science (held at the Aspen Institute, the Eastern Shore of Maryland, June $7-10,1991$ ). Industry spokespersons and animal husbandry faculty not particularly sympathetic to concerns about nonhuman animal welfare had no problem admitting that farm animals suffer from intense confinement; they disputed the importance of this fact.

${ }^{28}$ Harrison, op. cit., p. 82.

${ }^{29}$ Allan C. Wilson, "The Molecular Basis of Evolution," Scientific American 253(4), 1985, pp. 164-73.

${ }^{30}$ In a remarkable footnote, Harrison himself appears to concede that nonhuman animals can be intelligent, creative, and even learn genuine languages (footnote 8, p. 82). He makes no discernible attempt to square this admission with the claims made in the text of his paper.

${ }^{31}$ Ibid., p. 84.

${ }^{32}$ In this context, see Harrison's discussion of reflex behavior on p. 84. I will address this discussion separately below in the context of nonhuman animal learning.

${ }^{33}$ Donald Griffin has written extensively on this topic. See, e.g., his Animal Thinking (Cambridge, Mass.: Harvard U. Press, 1984). See also Daisy and Michael Radnor's
Animal Consciousness (Buffalo, N. Y.: Prometheus Books, 1989). See also Bernard Rollin, The Unheeded Cry, op. cit., and James Rachels, Ever Since Darwin, op. cit. For an excellent review of the ethological evidence and its ethical implications, see Marc Bekoff and Dale Jamieson, "Reflective Ethology, Applied Philosophy, and the Moral Status of Animals," Chapter One of Perspectives in Ethology, v. 9, P.P.G. Bateson and P.H. Klopfer, eds. (New York: Plenum Publishing, 1991).

${ }^{34}$ Harrison, op. cit., p. 84.

${ }^{35} \mathrm{Ibid}$.

${ }^{36} \mathrm{Ibid}$.

${ }^{37}$ Bernard Rollin, The Unheeded Cry, op. cit., pp. 145-6.

${ }^{38}$ Harrison, op. cit., p. 85.

${ }^{39}$ Richard Restak, M.D., The Brain (New York: Bantam Books, 1984), pp. 156, 162.

${ }^{40}$ Note that this phenomenon, if it could be shown to hold for nonhumans suffering violent attack, would not by itself license moral agents to treat them in these ways, any more than we would be licensed to do the same to humans. Individuals undergoing great physical trauma are gravely damaged, even if they might possibly not be suffering at that moment. If it were nevertheless permissible, which I doubt, to attack a nonhuman but not a human, it must be for some other reason.

${ }^{41}$ Harrison, op. cit., p. 86.

${ }^{42}$ Ibid., p. 87.

${ }^{43}$ He cites studies claiming, e.g., that opiates affect "the psychological context" of the brain rather than the nerve messages. We now know that opiates fill brain receptors, preventing transmission of the pain impulse from entering consciousness.

${ }^{44}$ Bernard Rollin, The Unheeded Cry, op. cit., p. 151.

${ }^{45}$ Harrison, op. cit., pp. 84-5.

$46 \mathrm{lbid}$, p. 85. As we shall see, although he tries to make sense of nonhumans' apparently learning from what we would experience as pain, he makes no attempt to account for the use of nonhumans in pain research. If he is right, one might as well use daisies. (Sadly, a great deal of our knowledge about pain mechanisms comes from a tradition of research on nonconsenting nonhumans. See Restak, op. cit., pp. 157-161.)

$$
\begin{aligned}
& { }^{47} \text { Ibid.,p.91. } \\
& { }^{48} \text { Ibid., p. } 85 .
\end{aligned}
$$


${ }^{49}$ Ibid., p. 83.

${ }^{50} \mathrm{Ibid}$

${ }^{51}$ Few would claim that nonhumans, as far as we know, are capable of conceptualizing moral principles and selfconsciously choosing to act in accordance with those principles. This does not mean that they cannot act virtuously, however. See Steve Sapontzis, Morals, Reason, and Animals, op. cit., pp. 43-44, on this issue.

${ }^{52}$ Harrison, op. cit., Footnote 8.

${ }^{53}$ That includes some theists. See, e.g., Andrew Linzey, Christianity and the Rights of Animals (New York: Crossroad Publishing Co., 1987); Steven Rosen, Food for the Spirit: Vegetarianism and the World Religions (New York: Bala Books, 1987); and Tom Regan, ed., Animal Sacrifices (Philadelphia, Pa.: Temple U. Press, 1986).

${ }^{54}$ Harrison, op . cit., p. 88.

55 Descartes, op. cit., p. 19.

${ }^{56}$ Harrison, op. cit., p. 91.

${ }^{57}$ Ibid., p. 90.

${ }^{58} \mathrm{Ibid} ., \mathrm{pp} .90-1$. He appears to be just as wrong about human infants as he is about nonhumans, as will be discussed below.

${ }^{59}$ Ibid. , p. 90.

${ }^{60}$ Harrison claims at one point that he is not denying that nonhuman animals are capable of remembering past experiences, since then they could not learn (p. 89). However, the only example of nonhuman learning he gives is the unconscious "learning" of a protozoan, as we have already seen. Moreover, the thought experiments he gives us would be utterly pointless without the claim, made explicitly, that nonhuman animals are akin to permanent amnesiacs. An amnesiac, by definition, has lost her memory. [A permanent amnesiac, he seems to think, would retain whatever has been "learned" in the past, without realizing that she learned it (p. 89). But this would only be the case for habitual actions, the very kind of actions that no longer rely on conscious recollection. A painful experience the previous day is quite another matter. Amnesiacs, in fact, do not remember persons who have hurt them (unless they regain their memories!).]

${ }^{61}$ Rollin, op. cit., p. 144.

${ }^{62}$ Carol Adams, "Abortion Rights and Animal Rights," Between the Species 7 (4), Fall 1991,181-9, p. 184.

${ }^{63}$ Harrison, op. cit., p. 90.

${ }^{64}$ Robert Langreth, "Pediatric Pain," Science News 139, February 2, 1991, pp. 74-75. See also the recent study by S.
Anand and P. R. Hickey in the January 2, 1992 issue of The New England Journal of Medicine. Some physicians were also concerned about the dangers of anesthetizing such tiny beings; the danger tums out to be in the opposite direction.

${ }^{65}$ D. D. Edwards, "Study Supports Easing Circumcision Pain,” Science News 133, March 19, 1988, p. 182.

${ }^{66}$ Langreth, op. cit., p. 75.

${ }^{67}$ Peter Carruthers, "Brute Experience," The Journal of Philosophy 86, 1989, pp. 258-269.

${ }^{68} \mathrm{Ibid}$, , p. 260.

${ }^{69}$ Edward Johnson, "Carruthers on Consciousness and Moral Status," op. cit.

${ }^{70}$ Carruthers, op. cit., p. 258.

${ }^{71}$ Ibid., p. 262.

${ }^{72}$ Ibid., p. 265. At first, Carruthers says that "most" of nonhuman experience is unconscious, but then he goes on to say that " $[t]$ he experiences of all these creatures will be of the nonconscious variety" (265). The discrepancy might be explained by the fact that he allows for the possibility that a few of the higher primates besides ourselves might have some conscious experiences, although be very much doubts it (ibid.)

${ }^{73}$ Ibid., p. 267.

${ }^{74}$ Ibid, p. 268.

${ }^{75}$ Ibid., p. 266.

${ }^{76}$ At the end of his article, Carruthers admits, like Harrison, that his view implies that infants and very young children must have no conscious experiences, including painful ones. He is unconcerned about the implication, noting only that mistreating them would nonetheless be wrong because one would risk damaging the persons they will become (269). As Johnson rightly notes, this implies that it would be fine to roast them alive on a spit if we know they will not survive infancy. (Johnson, op. cit., p. 192. The odious example is my own.) Carruthers takes no note of the fact that many permanently brain-damaged humans would also be machines on his view. Even quite typical adult humans may not be able at a given time to think about their thoughts about their experiences; on Carruthers' view, this would have to mean that they had nothing to think about in the first place!

${ }^{77}$ Edward Johnson, op. cit., p. 191. As Rollin points out, the verbal requirement for thought would make language acquisition impossible. See The Unheeded Cry. op. cit. pp. 138-9.

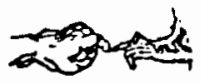

